\title{
COUNTERINTUITIVE INVESTMENT OPPORTUNITIES ON THE WSE. EVIDENCE FROM THE FIELD OF ASSET PRICING
}

How mispriced is the equity in emerging economies? We join this academic discussion by studying stock returns in today's Polish stock market. We test for abnormal excess returns using classic and modern asset pricing models. We report the evidence of certain time-varying return patterns that show investment potential. While size, investment, and momentum effects are not unequivocal enough to advertise them as trading opportunities, strategies based on profitability and value anomaly are evident and persistent throughout different investment climates. Counterintuitively, at an aggregated level we report a higher level of mispricing, and thus higher abnormal investment opportunities, in the period of bear market and stable macro-conditions (2000-2006) than during and after the recent global financial crisis (2007-2013). We advocate that in emerging stock markets like the Warsaw Stock Exchange, investors' asset pricing skills outweigh the effect of international portfolio rebalancing in the process of asset pricing.

Keywords: asset pricing model, emerging market, abnormal returns, international portfolio diversification

DOI: $10.15611 /$ aoe.2019.1.02

\section{INTRODUCTION}

An anomaly is a violation of the "paradigm-induced expectations that govern normal science" (Kuhn, 1970, pp. 52-53). In financial markets, an anomaly is a cross-sectional and time-series pattern in security returns that is not predicted by a model. A well-specified asset pricing model describes the relationship between risk and return and allows for the precise calculation of the required rate of return, leaving anomalous deviations from the intrinsic values the only source of mispricing. ${ }^{1}$ Importantly, the application of an

\footnotetext{
${ }^{*}$ Hult International Business School, San Francisco, Warsaw School of Economics.

** Haas School of Business, University of California, Berkeley.

${ }^{1}$ Every mispricing can be decomposed in the following way:
}

$$
V_{E}-P=(V-P)+\left(V_{E}-V\right)
$$

where $V_{E}-P$ represents the difference between the estimated value $V_{E}$ and observed value $P$ and is shown to be the sum of two components: 1) actual pricing anomaly, i.e. the difference between intrinsic value $V$ and observed value $P$, and 2) the difference between the estimated value $V_{E}$ and intrinsic value $V$, stemming from the imprecision of the estimate (pricing model). 
asset pricing model (hereafter 'APM') to study return patterns is always subject to a joint hypothesis problem (Fama 1991). Facing a joint hypothesis problem, one cannot determine if the anomalies are caused by the failure of an APM or rather they occur due to market inefficiency. Even if there is an empirical evidence for superior returns, it is impossible to judge if it stems from actual mispricing, sample-specific biases or model inaccuracy. The latter category further includes statistical limitations of the tests for efficiency. Most often, the reason for observing an anomaly will be a combination of a variety of factors, further hindering inference.

Throughout the years, scholars have been developing theoretical one and multi-factor asset pricing models that would explain what drives stock prices and determines counterpart returns. After the formation of CAPM - the most prominent of all APMs - researchers observed numerous market anomalies, e.g. size effect, value effect, short-term momentum, long-term reversal. Naturally, immediately after each anomaly was published, practitioners started exploiting them. This notwithstanding, some anomalies persist even a long time after they have been discovered and even though investors trade on them. This might happen due to at least two reasons: (i) an anomaly might have an unexplained risk component that distinguishes it from an arbitrage opportunity, which determines the long-term persistence of an anomaly, or (ii) an anomaly might persist due to the limits to arbitrage, i.e. borrowing, computational, or informational constraints, etc. In general, exploiting an anomaly is more difficult than spotting it, especially in markets with restricted short sales, margin trades, and access to hedging instruments.

Against this backdrop, we join the above-described academic narrative by addressing the following question: which anomalies in emerging stock markets provide investors with outstanding investment opportunities? In particular, we conduct an empirical analysis of the Polish stock market to reveal some local-specific return patterns that result directly from the unique characteristics of the domestic investment environment and its transformation over time. We chose the Warsaw Stock Exchange (hereafter 'WSE') to be the primary focus of our study because it is an excellent example of a young, developing stock market, which, within the first 25 years of its existence, became a regional hub for listing and investing.

In this paper we seek to shed light on which investment strategies prevail on the WSE regardless of the bull and bear market, i.e. during the period 2000-2013. Thus we analyze the performance of portfolios formulated in accordance with five generic trading strategies, i.e. portfolio formation rules designed to capture anomalous returns related to: size (small and big market 
capitalization), value (high and low book-to-market), momentum (past winners and past losers), profitability (robust and weak operating profitability), and investment (aggressive and conservative investment policy). Portfolio creation is rooted in the asset pricing theory and is performed in line with the conventional procedures of the asset pricing tools' empirical application.

Another succinct question is to what extent equity in emerging economies is mispriced. Building on Barberis and Thaler (2003), who argue that return predictability reflects mispricing, we contribute to this discussion by testing for mispricing on the WSE. In our study, we use asset pricing models and refer to the concept of an abnormal return - an additional return on a stock or portfolio that exceeds the return predicted by a model. Consequently, the abnormal return constitutes a pricing anomaly. To this point, portfolio returns serve as dependent variables in our time-series regressions to price anomalies. First, we run the regressions separately on each portfolio. Second, we test for abnormal returns at an aggregated level, notably we use two different asset pricing models. In doing so, we mitigate the joint hypothesis problem and avoid claiming primacy of one model over another. The latter is a separate ongoing debate, as none of the asset pricing models have so far proved to be superior. Empirical research provides evidence that any model, once employed in a particular stock market, can give contradictory results for pricing efficiency in particular in periods selected by researchers. We expect that the incoherent results are largely driven by the stylized fact that financial markets are not homogenous in terms of their stage of development, nor are they stable over time.

Considering that our sample period encompasses both a bullish (20002006) and a bearish (2007-2013) market, we then divide it into two subperiods respectively. Intuitively, due to the changing investment climate and the rapid development of the Polish stock market, we expect that in these two periods the level of mispricing, and thus investment opportunities on the WSE would be different. Is the detachment of stock prices from fundamentals higher in a time of crisis because foreign investors rebalance their international portfolios? Or rather is the level of inefficiency in pricing related to asset pricing skills? We begin with the initial expectation that, unlike in the advanced capital markets, stock price valuation on the WSE in the period of and after the recent global financial crisis (2007-2013) exhibited very high abnormal returns with respect to particular types of companies due to the impact of foreign investors' trade and its consequences in the form of spillover effects. If macroeconomic, political and other factors originating in developed economies cause short (and often long) term shocks that are echoed in emerging stock markets, then pricing on the WSE is 
responding to global events rather than rigorously following fundamentals. This is in line with Schotman and Zalewska's (2006) observation that the WSE is materially susceptible to global movements in asset pricing, although the correlation coefficients decreased over time, and with Prorokowski and Roszkowska's (2014) empirical evidence that the Polish stock exchange continues to demonstrate many characteristics of an underdeveloped capital market. Therefore, the asset pricing skills have remained low in recent years. Additionally, if foreign investors made up almost half of the trading volume on the WSE, this could have escalated the detachment of stock prices from their fundamentals even further. Conversely, in recent years, foreign institutional investors might have contributed to a more precise pricing with their advanced asset pricing skills. This is an argument for decreasing abnormal returns that would also be in line with the macroeconomic outstanding performance of the Polish economy during and after the global financial crisis of 2007-2008. It is ex ante unclear which of these factors play a more pivotal role in determining mispricing on the WSE. Running separate asset pricing tests on successive time-series allows for assessing the impact of the changing investment environment on pricing accuracy and the general results of abnormal investment opportunities on the WSE.

As it transpires, two generic trading strategies stand out as particularly prominent in the Polish stock market. Investment opportunities related to the profitability anomaly are the most evident and robust. Taking advantage of the value effect relies on shorting as the abnormal returns are only statistically supported for growth stocks. We observe momentum-related profits, but we abstain from concluding about underlying anomaly because, contrary to the evidence from other stock markets, both winner and loser stocks on the WSE yield positive abnormal returns. While both asset pricing models perform similarly well in explaining cross-section variation in stock returns on the WSE, we are more inclined to give primacy to the Fama and French three-factor model (based on five different performance measures). More importantly, accounting for the differences in investment climates between the periods of 2000-2016 and 2007-2013, we counterintuitively observe less mispricing during and after the recent global financial crisis. Therefore, we argue that asset pricing skills had a stronger impact on asset pricing on the WSE than the spillover effect and international portfolio diversification consequences.

The paper is organized as follows. In Section 2 we provide a literature review on the evolution of asset pricing tools and empirical arguments on what drives asset mispricing in stock markets. Section 3 provides an 
explanation of our identification strategy. In Section 4 we present the data sample. In Section 5 we document and discuss our results, and in Section 6 we conclude.

\section{STUDY BACKGROUND}

Although stock price valuation has been attracting practitioners' attention since early trading on the first stock exchanges, only over the last five decades it has become one of the cornerstones of finance. An original survey by Fama (1970) provides the very first summary of earlier work on the movements of stock prices and clarifies the concept of mispricing in capital markets.

The original capital asset pricing model (CAPM) was developed in the mid-1960s by Sharpe (1964) and Lintner (1965). It was based on the modern portfolio theory introduced by Markowitz (1953). Later, it was modified by Black (1972) to the form we know of now. Since then, various studies have emerged in the appraisal of the CAPM actual performance. A prominent example is the assessment of the beta's explanatory power by Fama and Macbeth (1973). That paper became known for the unique cross-sectional method introduced to test the CAPM model, and later often replicated to test other models. The validity of the market portfolio as a single factor was questioned by Roll (1977) who advocated that market proxy in a form that complies with the original assumptions of portfolio theory is unobservable in practice, and hence cannot be used to explain expected returns. The evidence that the relation between beta and average return is too flat was confirmed in time-series tests such as those by Friend and Blume (1970), Black, Jensen and Scholes (1972), Stambaugh (1982). Constantinides (1982) contributed to the topic by noting the issue of consumer heterogeneity. Since investors are not homogenous, an asset's risk premium cannot be determined only by the covariance with market return (and beta as a measure of sensitivity) but is also dependent on all, individual expectations. These expectations cannot be aggregated into a market portfolio under the assumption of homogeneity.

Some of the critique is directed not specifically at the model's specification itself but at the entire market efficiency concept, and hence the legitimacy of making use of such models to price financial assets. For example, Banz (1981) described the 'size effect' and discovered empirically that small stocks (i.e. stocks with relatively low market capitalization) outperform bigger stocks. His discovery was a serious blow at both efficiency and asset-pricing, since neither could account for the documented anomaly. Apart from further confirmation of the size effect, Fama and French (1992) documented that stocks with high book-to-market ratios provide higher results in comparison to low book-to-market ratio stocks. 
Questioning the original CAPM model resulted in the further development of the asset pricing theory. For instance, the two previously mentioned anomalies (small stocks outperforming big stocks and high bookto-market ratio stocks outperforming low book-to-market ratio stocks) were eventually incorporated into the new asset pricing model of Fama and French (1993), henceforth known as the Fama and French three-factor model. Replacing CAPM, the three-factor model soon dominated assetpricing practice. Yet, it too was eventually criticized - it turned out that neither CAPM nor the Fama and French three-factor model were robust enough to capture the momentum anomaly of Jegadeesh and Titman (1993). Then Carhart (1997) incorporated momentum into the Fama and French three-factor model as an additional risk factor. Similarly, Fama and French complemented their three-factor model with investment and profitability risk factors. Over time, as the new anomalies were discovered, scholars have been developing new, presumably better, asset pricing models based on what risk factors seemed to be priced.

The process of capturing new anomalies has been closely observed by academics, but mostly by market practitioners. Reflecting on the phenomenon of anomalies, one may conclude that each has an intrinsic, selfdestructing tendency - as the new anomaly is discovered, sophisticated investors, with the help of academic research on asset pricing, learn how to identify its existence and benefit from trade on securities. Ultimately the potential profits are distributed among those investors, and equity becomes less mispriced. Importantly, the process of reaching equilibrium via arbitrage trading is conditional on how strong the limits to arbitrage are, as described in Grossman and Stiglitz (1980). However, the general tendency is always towards more precise pricing. Further, the transformation of stock markets is a social, and not physical process, therefore it is subject to behavioral biases. Behavioral finance is the field in finance that aims to provide answers to questions of why prices diverge from fundamentals and why investors should not be considered to be perfectly rational and hence accurate in their estimations and expectations. Among others, Malkiel (2003) and Shiller (2003) link the efficiency theory and thus mispricing to the insights of behavioral finance and derive implications for securities' valuation and investments. Recently researchers have been examining the concept of investors' sentiment (understood as a general market attitude) revealed in investors' actions, but often unwarranted by fundamentals. On this point, Baker and Wurgler (2006) derive implications of the investor sentiment for asset pricing.

Additionally, the investors' composition also strongly affects asset pricing in emerging financial markets. On the one hand, investors from 
advanced stock markets tend to have higher asset pricing skills. On the other hand, they treat their investment in emerging equity as a secondary priority. The behavior of foreign investors can distort pricing in emerging markets, particularly in times of economic distress. In the event of a global crisis, international investors tend to withdraw their funds from markets they consider riskier. Their behavior is an element of a crisis contagion mechanism - the irrational fears lead to the high co-movement of prices resulting from withdrawals (King and Wadhwani, 1990). The effect will be particularly pronounced on the downside, creating price pressure in the result of asset fire sales. Alternatively, international shock transmission may have a somewhat more rational justification. According to Longstaff (2010), global investors may be particularly limited in making their portfolio allocation decisions by the restricted access to funding, thus they will tend to withdraw their investments because of insufficient liquidity. In addition to higher perceived riskiness and lower liquidity, limited information is said to be another major difficulty in investing in emerging markets (Chuhan, 1994), potentially strengthening the motivation for withdrawals. In addition, since the increased number of speculators generally contributes to market efficiency by improving pricing accuracy (Grossman, 1995), the diminishing activity of international investors may likely cause the opposite effect. Therefore it seems reasonable to expect higher pricing distortions (as evidenced by the enhanced abnormal returns) during times of global market turmoil in the emerging stock exchanges with a large (yet volatile) representation of foreign investors.

Empirical research in the area of asset pricing in the emerging markets of Central and Eastern Europe (CEE) has so far been focused on testing for market integration of the CEE stock exchanges (Schotman and Zalewska, 2006), examining the historical performance of mutual funds on the WSE (Białkowski and Otten, 2011) or verifying the risk-return relationship according to different specifications of classic asset pricing models (Waszczuk, 2013a; Waszczuk, 2013b). Zaremba and Konieczka (2015) provide evidence on investment opportunities related to size, value and momentum trading strategies, accounted for liquidity and transaction costs constraints jointly for eleven CEE stock markets. Their conclusions are limited due to using only one asset pricing model (the joint hypothesis problem) and not accounting for the heterogeneity of these markets. The purpose of our study is fundamentally different from these analyses as we focus on the profitability of specific trading strategies according to onefactor and multi-factor asset pricing models and present the results accounting for different investment climates (and the contemporaneous stage 
of development of the Polish stock market). Our paper aims to analyze the investment opportunities due to persistent patterns in mispricing. The empirical part that follows is based on the application of asset pricing tools in order to distinguish the prevalent anomalies on the WSE.

\section{IDENTIFICATION STRATEGY}

\subsection{Asset pricing models}

To test for abnormal returns in the Polish stock market, we employ two different asset pricing models. As a universal approach towards model estimation and testing, we use the classic cross-sectional analysis as in Fama and French (1993). This requires sorting stocks in order to control for changes in underlying risk factors and running time-series regressions on the various portfolios (allowing for particular assets to switch portfolios when the underlying factors change).

In general, every asset pricing model can be conveniently presented in the following form:

$$
R_{i, t}=\alpha_{i}+\beta_{i}^{1} \lambda_{i, t}^{1}+\beta_{i}^{2} \lambda_{i, t}^{2}+\cdots+\beta_{i}^{m} \lambda_{i, t}^{m}+\varepsilon_{i, t}
$$

or, equivalently:

$$
\boldsymbol{R}_{t}=\boldsymbol{\alpha}+\boldsymbol{\beta} \lambda_{M t}+\boldsymbol{\varepsilon}_{t}
$$

where $\boldsymbol{R}_{t}$ is a $(N \times 1)$ vector of excess returns (basically $\left.\boldsymbol{r}_{t}-r_{f, t}\right)$ for $N$ assets, $\boldsymbol{\alpha}$ is an $(N \times 1)$ vector of intercepts, $\lambda_{M t}$ is a $(M \times 1)$ vector of $M$ factors used to describe the returns, $\boldsymbol{\beta}$ is a $(N \times M)$ matrix of factor sensitivities, and $\boldsymbol{\varepsilon}_{t}$ is an $(N \times 1)$ vector of disturbances.

Accordingly, to explain excess stock returns we examine regressions (Equations 4 and 5) that use only the excess market return (a) or that use other multifarious risk factors as covariates (b):

a) The Capital Asset Pricing Model of Sharpe (1964) and Lintner (1965) (thereafter CAPM):

$$
R_{i, t}-r_{f, t}=\alpha_{i}+b_{i} M K T_{t}+\varepsilon_{i, t}
$$

where $R_{i, t}$ is the actual monthly return on a given portfolio $i$ at time $t, r_{f, t}$ is the return on the risk-free asset, $\alpha_{i}$ is the intercept, $M K T_{t}$ is the market excess return and the corresponding factor sensitivity $b_{i}$, and $\varepsilon_{i, t}$ is the error term. The market factor is the difference between a proxy for market return and the risk-free rate. 
b) The Fama and French three-factor model of (1993) (thereafter FF3F):

$$
R_{i, t}-r_{f, t}=\alpha_{i}+b_{i} M K T_{t}+s_{i} S M B_{t}+h_{i} H M L_{t}+\varepsilon_{i, t}
$$

where the original CAPM regression is enhanced with two additional factors: size factor $S M B_{t}$ (small minus big market cap), meant to mimic the risk factor in returns related to size, and $H M L_{t}$ (high minus low book-to-market) used to represent the risk factor in returns related to book-to-market equity $(\mathrm{B} / \mathrm{M})$ and the corresponding factor sensitivities, denoted by $s_{i}$ and $h_{i}$. To proxy for size, we calculate market capitalization (non-adjusted stock price times the number of common shares outstanding). B/M ratio is the book equity (total assets minus total liabilities) divided by market capitalization. Each factor is constructed with $2 \times 3$ independent sorts. To do so, stocks are allocated into two size groups (Ssmall, B-big) and three B/M groups (H-high, L-low, M-medium). We use the median of market cap for size breakpoint and $30^{\text {th }}$ and $70^{\text {th }}$ decile of $\mathrm{B} / \mathrm{M}$ for stocks for $\mathrm{B} / \mathrm{M}$ breakpoint. We calculate six value-weight portfolios from intersections of both sorts. Monthly value-weighted returns on the six portfolios are calculated from July of year $t$ to June of year $t+1$ and the portfolios are reformed in June of $t+1$ so that the portfolios are rebalanced yearly. The sixmonth gap between year-end $t-1$ and July $t$ is to ensure that the accounting variables from year $\mathrm{t}-1$ are known. In line with conventional procedure, the SMB factor is the difference, each month, between the simple average of the three small stock portfolio returns and the simple average of the three big stock portfolio returns. The HML factor is the difference, each month, between the simple average of the two high $\mathrm{B} / \mathrm{M}$ portfolio returns and the average of the two low $\mathrm{B} / \mathrm{M}$ portfolio returns.

Particular models' specification varies depending on the choice of risk factors, for example in a classic CAPM model, an excess market return is used as the proxy for a single market factor. In multi-factor models, riskreturn relationship is also attributed to other risk factors, e.g. the size factor. By running time-series regressions on the selected models, we estimate the corresponding factor sensitivities.

\subsection{LHS portfolios}

Despite founding our inference on time-series regressions, we still acknowledge the cross-sectional character of our research. To address this aspect, stocks are first sorted into left-hand side (hereafter LHS) portfolios. LHS portfolios are the basis for anomaly verification (inferring on persistent profitable trading strategies) and general robustness testing. Academic studies provide support for dozens of anomalies. McLean and Pontiff (2016) 
examine 97 anomalies that are presumed to predict the cross-section of stock returns. To this point, Edelen et al. (2016) show that institutional investors in the U.S. stock markets tend to trade against anomalies assigned to seven broader categories: valuation, profitability, corporate investment, earnings quality, financing, financial distress and momentum. We provide a slightly broader spectrum of the most popular anomalies (as used in academic research and by stock market practitioners) in Table 1.

\section{Table 1}

Popular stock sorting categories

We provide a succinct overview of possible stock sorting categories that are derived from asset pricing literature and represent the most influential anomalies published to date. Based on past empirical research, these sorts have been advocated to constitute an anomaly in stock pricing. Thus, all are good candidates to reveal potential mispricing, depending on the market and the model under research. For instance, trade persistence or ICT may not be appropriate for the Polish market, and distress may not be appropriate for FF3F since HML proxies for it

\begin{tabular}{|c|c|c|}
\hline $\begin{array}{c}\text { Category } \\
\text { (Anomaly) }\end{array}$ & Details & Related research \\
\hline 1 & 2 & 3 \\
\hline Size & $\begin{array}{l}\text { Stocks are sorted on size (price multiplied by number of shares } \\
\text { outstanding). Median breakpoint is used to split the sample into } \\
\text { two groups, small and big (Small group usually consists of more } \\
\text { stocks but constituting less than half total market capitalization). } \\
\text { Alternatively, stocks can be sorted into three or more groups using } \\
\text { relevant breakpoints. Size category is frequently used in bivariate } \\
\text { portfolios as a controlling dimension. }\end{array}$ & $\begin{array}{l}\text { Banz (1981), Fama and } \\
\text { French (1993), Fama } \\
\text { and French (2008) }\end{array}$ \\
\hline $\begin{array}{l}\text { Book-to- } \\
\text { market }\end{array}$ & $\begin{array}{l}\text { Stocks are usually sorted into three book-to-market equity } \\
\text { groups based on, for example, breakpoints from the bottom } \\
30 \% \text { (Low), middle } 40 \% \text { (Medium) and top } 30 \% \text { (High) of } \\
\text { the ranked values of BE/ME. The BE/ME ratio is favored in } \\
\text { the academic research. The reciprocal, P/B ratio, is frequently } \\
\text { used in practice. High book-to-market proxies for value } \\
\text { stocks, also associated with low P/B, low P/E and/or high } \\
\text { dividend yield metrics. Low BE/ME represents growth stocks. }\end{array}$ & $\begin{array}{l}\text { Fama and French } \\
\text { (1993), Fama and } \\
\text { French (1992), } \\
\text { Asness and Frazzini } \\
(2013)\end{array}$ \\
\hline Momentum & $\begin{array}{l}\text { Past winners tend to systematically outperform past losers in } \\
\text { the successive periods. Testable momentum portfolios are } \\
\text { traditionally formed in a two-step procedure. First, the } \\
\text { winners (and the losers) are determined in the formation } \\
\text { period, usually lasting } 6 \text { to } 12 \text { months. Second, the returns for } \\
\text { corresponding portfolios are calculated for the following } 6 \text { to } \\
12 \text { months, the period known as a holding period. Often, the } \\
\text { holding period is preceded by short, usually 1-month-long, } \\
\text { skip period to avoid short-term return distortions. }\end{array}$ & $\begin{array}{l}\text { Jegadeesh and Titman } \\
(1993)\end{array}$ \\
\hline Distress & $\begin{array}{l}\text { There is a negative relation between financial distress and } \\
\text { average returns. To test for this relationship, stocks can be } \\
\text { sorted by, for example, the distress measure of Campbell, } \\
\text { Hilsher and Szilagyi (2008) or Ohlson's (1980) O-score, } \\
\text { which represents failure probability. In practice, value factor } \\
\text { (BE/ME) is considered a good proxy for financial distress. }\end{array}$ & $\begin{array}{l}\text { Campbell, Hilsher and } \\
\text { Szilagyi (2008), } \\
\text { Ohlson (1980) }\end{array}$ \\
\hline
\end{tabular}




\begin{tabular}{|c|c|c|}
\hline 1 & 2 & 3 \\
\hline $\begin{array}{l}\text { Net Stock } \\
\text { Issues }\end{array}$ & $\begin{array}{l}\text { Net stock issues can be measured as the natural logarithm of } \\
\text { the ratio of the split-adjusted shares outstanding at the fiscal } \\
\text { year-end in t- } 1 \text { divided by split-adjusted shares outstanding at } \\
\text { the fiscal year-end in t- } 2 \text {. The factor measures the impact of } \\
\text { the seasoned equity offerings, stock repurchases, or reverse } \\
\text { splits on the stock returns. }\end{array}$ & $\begin{array}{l}\text { Fama and French } \\
(2008), \text { Daniel and } \\
\text { Titman (2006), Pontiff } \\
\text { and Woodgate (2008) }\end{array}$ \\
\hline $\begin{array}{l}\text { Asset } \\
\text { growth } \\
\text { (Investment) }\end{array}$ & $\begin{array}{l}\text { Asset growth can be measured as total assets at fiscal year- } \\
\text { end of } \mathrm{t}-1 \text { minus total assets at fiscal yearend of } \mathrm{t}-2 \text { divided by } \\
\text { total assets at fiscal year-end of } \mathrm{t}-2 \text {. The factor, together with } \\
\text { the profitability factor, supplements the size and value factors } \\
\text { in the Fama and French five-factor model. }\end{array}$ & $\begin{array}{l}\text { Cooper, Gulen and } \\
\text { Schill (2008), Fama and } \\
\text { French (2015) }\end{array}$ \\
\hline $\begin{array}{l}\text { Earnings } \\
\text { surprises }\end{array}$ & $\begin{array}{l}\text { One possible measure of the earnings surprises is the standard } \\
\text { unexpected earnings (SUE) metric, which is unexpected } \\
\text { earnings divided by the standard deviation of the unexpected } \\
\text { earnings. Stocks are than ranked each month based on their } \\
\text { most recent SUE. }\end{array}$ & $\begin{array}{l}\text { Foster, Olsen and } \\
\text { Shevlin (1984), Chan, } \\
\text { Jegadeesh and } \\
\text { Lakonishok (1996) }\end{array}$ \\
\hline Industries & $\begin{array}{l}\text { Portfolios can be simply sorted into industry portfolios, using } \\
\text { existing classification methods (i.e. US SIC codes) or other } \\
\text { criteria. }\end{array}$ & $\begin{array}{l}\text { Chou, Ho and Ko } \\
\text { (2012) }\end{array}$ \\
\hline Profitability & $\begin{array}{l}\text { Profitability can is measured in various ways, usually as a } \\
\text { ratio of income to book value. }\end{array}$ & $\begin{array}{l}\text { Fama and French (2008), } \\
\text { Fama and French (2006), } \\
\text { Fama and French (2015), } \\
\text { Haugen and Baker } \\
\text { (1996), Cohen, Gompers, } \\
\text { and Vuolteenaho (2002) }\end{array}$ \\
\hline Accruals & $\begin{array}{l}\text { Accruals, can be measured as a change in operating working } \\
\text { capital per split-adjusted share from } t-2 \text { to } t-1 \text { divided by book } \\
\text { equity per split-adjusted share at } t-1 \text {. Higher accruals proxy for } \\
\text { lower earnings quality and thus is associated with lower returns. }\end{array}$ & $\begin{array}{l}\text { Sloan (1996), Fama and } \\
\text { French (2008) }\end{array}$ \\
\hline $\begin{array}{l}\text { Trade } \\
\text { persistence }\end{array}$ & $\begin{array}{l}\text { Net institutional trade has been modelled using percentage } \\
\text { change in the volume of shares of a particular stock in } \\
\text { institutional investors' portfolios. Above-average stocks are } \\
\text { considered net buys and below-average buys - net sells. } \\
\text { Persistence measures a number of consequent quarters of } \\
\text { being either net buy (positive) or net sell (negative). }\end{array}$ & Dasgupta et al. (2011) \\
\hline $\begin{array}{l}\text { Technology } \\
\text { Shocks }\end{array}$ & $\begin{array}{l}\text { Technology shocks can be measured using an IMC factor, } \\
\text { which is the difference between investment goods producers' } \\
\text { returns and consumer goods producers' returns. Using the } \\
\text { IMC measure, stocks can be grouped on the basis of their beta } \\
\text { sensitivity to this factor. }\end{array}$ & $\begin{array}{l}\text { Kogan and } \\
\text { Papanikolaou (2011) }\end{array}$ \\
\hline $\begin{array}{l}\text { CAPM } \\
\text { Betas }\end{array}$ & $\begin{array}{l}\text { Stocks can be sorted on the basis of their CAPM betas. This } \\
\text { requires first running initial pre-sort regressions to estimate betas } \\
\text { than run regressions and estimate betas again. This represents the } \\
\text { classic verification of CAPM beta's explanatory power. }\end{array}$ & $\begin{array}{l}\text { Fama and MacBeth } \\
\text { (1973), Fama and } \\
\text { French (1992) }\end{array}$ \\
\hline $\begin{array}{l}\text { Liquidity } \\
\text { Betas }\end{array}$ & $\begin{array}{l}\text { This factor represents innovations in aggregate market } \\
\text { liquidity. Monthly aggregate liquidity measure is a cross- } \\
\text { sectional average of individual-stock liquidity metric called a } \\
\text { gamma - regression-based measure capturing the effect of } \\
\text { trading volume on prices. }\end{array}$ & $\begin{array}{l}\text { Pastor and Stambaugh } \\
\text { (2003) }\end{array}$ \\
\hline
\end{tabular}

Source: authors' own. 
In our study we employ five different sorting categories resembling the generic strategies we are considering, which also meet the case of the empirical evidence provided by Edelen et al. (2016). An important thing to note is that although some LHS portfolios are designed to mimic RHS factor portfolios, they may follow a slightly altered formation and rebalancing principles. First, we construct two size portfolios: Small and Big. The size factor is the obvious choice as the related anomaly is probably the most widely known one. Second, we construct two value portfolios: High, with value stocks, and Low, with growth stocks. The two sorting strategies, size and value, resemble the corresponding factors from the Fama and French three-factor model in that the stocks are sorted on their market capitalization and book-to-market ratio accordingly. In constructing LHS portfolios, however, we sort stocks from both categories into three different groups, using $30^{\text {th }}$ and $70^{\text {th }}$ percentile breakpoints. Third, we account for the popular momentum trading strategy. In constructing Winner and Loser portfolios, we employ the 12/1/12 convention. Thus we form portfolios on the basis of the prior 12 months, we skip a single period and then we calculate returns for the following 12 months. Fourth, we investigate the profitability anomaly by sorting stocks into Robust-profitability and Weak-profitability stocks. In doing so we focus on the operating profit, appropriately adjusted and scaled:

$$
O P=\frac{o p_{\text {profit }}-f i n_{\text {costs }}}{B E}
$$

where $o p_{\text {profit }}$ is the operating profit, $f i n_{\text {costs }}$ represents financial costs and $B E$ is the book value of equity. Finally, we also sort stocks on the basis of their investment policy into Aggressive-investment stocks and Conservativeinvestment stocks. As a basis for portfolios formation we use breakpoints based on the following metric:

$$
\operatorname{Inv}=\frac{\text { Assets }- \text { Assets }_{\operatorname{lag}(12)}}{\text { Assets }},
$$

where Assets denotes the total assets as reported in the most recent balance sheet, and Assets $_{\operatorname{lag}(12)}$ represents 12-month-lagged total assets, reported in the second-most-recent financial statements.

We reduce the number of sort dimensions to one and we limit the number of breakpoints used to subset the sample to three, which is in contrast to the hitherto mainstream empirical research in asset pricing. The reasonable minimum is established because of the constraints implied by the relatively 
low number of stocks in the sample, especially in the beginning of the sample.

Apart from momentum portfolios, all portfolio returns are value-weighted. We use equal weighting with respect to Winner and Loser portfolios, since value weighting magnifies momentum returns by outweighing top-performing stocks. Table 2 briefly describes the LHS portfolios used in the study and summarizes the relevant formation rules.

Table 2

LHS portfolios description

We asses five generic trading strategies, related to size, value, momentum, profitability and investment. To evaluate the strategy, we separately form two portfolios from the extreme top and bottom $30 \%$ stocks sorted on the metric relevant for each of those five categories

\begin{tabular}{l|l}
\hline \multicolumn{1}{c|}{ Portfolio } & \multicolumn{1}{c}{ Description } \\
\hline Small & $\begin{array}{l}\text { LHS Small-stock portfolio; value-weighted return on all stocks in the bottom } \\
30 \% \text { of stocks sorted on market capitalization. }\end{array}$ \\
\hline Big & $\begin{array}{l}\text { LHS Big-stock portfolio; value-weighted return on all stocks in the top 30\% } \\
\text { of stocks sorted on market capitalization. }\end{array}$ \\
\hline High & $\begin{array}{l}\text { LHS High-book-to-market stock portfolio; value-weighted return on all } \\
\text { stocks in the bottom 30\% of stocks sorted on book-to-market ratio. }\end{array}$ \\
\hline Low & $\begin{array}{l}\text { LHS Low-book-to-market stock portfolio; value-weighted return on all stocks } \\
\text { in the top 30\% of stocks sorted on book-to-market ratio. }\end{array}$ \\
\hline Winner & $\begin{array}{l}\text { LHS Winner-stock portfolio; equally-weighted return on all stocks in the top } \\
30 \% \text { of stocks sorted on prior returns. }\end{array}$ \\
\hline Loser & $\begin{array}{l}\text { LHS Loser-stock portfolio; equally-weighted return on all stocks in the } \\
\text { bottom 30\% of stocks sorted on prior returns. }\end{array}$ \\
\hline Robust & $\begin{array}{l}\text { LHS Robust-profitability stock portfolio; value-weighted return on all stocks } \\
\text { in the top 30\% of stocks sorted on operating profitability }(O P) .\end{array}$ \\
\hline op & $\begin{array}{l}\text { LHS Weak-profitability stock portfolio; value-weighted return on all stocks } \\
\text { in the bottom 30\% of stocks sorted on operating profitability }(O P) \text {. }\end{array}$ \\
\hline Aggressive & $\begin{array}{l}\text { LHS Aggressive-investment stock portfolio; value-weighted return on all } \\
\text { stocks in the top 30\% of stocks sorted on operating profitability }(I N V) .\end{array}$ \\
\hline Conservative & \multicolumn{1}{|c}{} \\
\hline
\end{tabular}

Source: authors' own.

\subsection{Testing for model's robustness}

Further, we study abnormal returns across different portfolios and at an aggregated level. The ultimate conclusions with respect to investment opportunities on the WSE are drawn on the basis of estimates averages and the model's performance measures. In line with the conventional view in asset pricing theory, asset pricing models should be able to comprehensively explain the risk-return relationship solely by the incorporated risk factors. 
Note that the equation from the beginning of the section does not include intercepts. This is because, on theoretical grounds, an intercept is interpreted as an abnormal return, i.e. the 'persistent portion' of return that is left unexplained by the risk factors incorporated in a given model. The straightforward way to verify a model's robustness is to test the statistical significance of its intercept $\alpha$ . This can be done for every portfolio separately (using basic statistical inference) or jointly for all intercepts using the GRS test (Gibbons, Ross and Shanken, 1989). The null hypothesis of joint insignificance of alphas allows us to examine the model's explanatory power:

$$
H_{0}: \quad \alpha_{i}=0, \quad i=1, \ldots, N .
$$

against the alternative $H_{1}: \alpha_{i}<0$ for at least one $i$. The test itself is:

$$
\left(\frac{T}{N}\right)\left(\frac{T-N-L}{T-L-1}\right)\left[\frac{\hat{\alpha}^{\prime} \hat{\Sigma}^{-1} \hat{\alpha}}{1+\bar{\mu}^{\prime} \hat{\Omega}^{-1} \bar{\mu}}\right] \sim F(N, T-N-L) .
$$

Among input variables, $T$ are the time periods, $N$ is a number of assets (portfolios), $L$ is a number of factors, $\hat{\alpha}$ is an estimated intercept vector, $\hat{\Omega}$ is an estimate of the factor covariance matrix, $\bar{\mu}$ is a vector of sample factor mean returns and $\hat{\Sigma}$ is an estimate of the covariance of residuals. The test uses $\mathrm{F}$ distribution with $\mathrm{N}$ and $T-N-L$ degrees of freedom. However, in order to perform statistical analysis of the model's specification, that is the significance of risk factors incorporated in model, we must run an additional set of strictly cross-sectional regressions. One of the most common approaches is the classic Fama-Macbeth two-stage regression (see Fama and Macbeth, 1973).

As in previous research, our tests are subject to the joint hypothesis problem (Fama 1991). This, among others, means that our evaluation of model performance is conditional on distributional assumptions of returns and residuals. Specifically, the commonly employed GRS test is biased towards the over-rejection of market efficiency if the normality assumption of the distribution of returns and residuals is violated (Zhou, 1993). Our motivation for the choice of the methodology was the ease of comparison of our results from the WSE with the results from advanced markets. Furthermore, the above concerns are alleviated in relative comparisons between time periods and across models.

Finally, we focus on the models' relative performance and we conclude on the investment opportunities indicated by each model, accounting for all limitations that apply. Last but not least, we conclude on the relative 
investment opportunities in different market climates (bull $v s$. bear market) by examining regression parameters, intercepts in particular, for two periods separately: 2000-2006 and 2007-2013. So far we have only presented results at an aggregated level.

\section{DATA SAMPLE}

We use the Warsaw Stock Exchange as an example of an emerging market in our study because of its outstanding position in the region and as an interesting case in general. The WSE is one of the major European stock exchanges, and definitely the leader in Central and Eastern Europe. Since it reopened in 1991, the Polish stock market has undergone a material transformation, gradually overcoming its shortcomings such as institutional impediments, small size, weak corporate governance and macroeconomic volatility. Although it currently constitutes an interesting option for listing and investing, Prorokowski and Roszkowska (2014) show that the WSE still exhibits many characteristics of an underdeveloped capital market. Sizewise, the WSE is a leading bourse not only in the CEE region. In 2013, it ranked 2nd among all the European exchanges regarding the number of IPOs (PwC, 2014). The high number of IPOs was also followed by outstandingly high offered value $(\mathrm{PwC}, 2014)$. This growth has been attracting foreign institutional investors, and this group has been constantly growing in significance in terms of turnover volume. Similarly, more and more foreign companies list on the WSE - 47 out of the 450 firms listed in 2013 were foreign entities.

The sample is based on financial information for the universe of firms listed in Poland: in the Warsaw Stock Exchange (Main List). For each stock we use stock return files and corporate files with accounting data. We derive available daily stock prices and trading volume from the data providers: Stooq.pl and Bossa.pl (for split and dividend adjusted and non-adjusted prices, respectively). We calculate arithmetic stock returns and compound them monthly by multiplication. We use accounting information from the Notoria Serwis. We merge both databases at a firm-level using the company's ticker and manually cross-check to ensure the completeness of our ultimate database.

Table 3 summarizes the universe of stock listed companies on the WSE in the period 2000-2013, which constitutes our sample under research. We trim the sample so that it starts in January 2000 in order to ensure robust inferences, as in aforementioned years there were too few companies listed on the WSE to draw statistically significant conclusions. Moreover, we are 
restricted by the availability of accounting data and the necessity for lagged data to calculate risk factors. To this point, we realize that the data sample we use can be perceived as a research limitation. In comparison to data for advanced stock markets it is still a short period, hence sometimes our estimates are not as significant as their equivalents in advanced capital markets. Another limitation of our sample is that it includes relatively few stocks, which affects our approach towards sorting. To ensure the validity of statistical inference we alter the standard sorting procedures to acknowledge the sample limitations. The possible solutions include reducing the number of dimensions addressed in forming intersect portfolios, or limiting the number of breakpoints used to subset the sample.

Table 3

Sample under research

We run our tests on the period of January 2000-December 2013, 168 monthly observations. Market Cap. is the total market capitalization in billion PLN. No. of Companies is the number of the companies listed on the WSE at the end of each year

\begin{tabular}{c|c|c|c|c|c}
\hline Year & $\begin{array}{c}\text { Market } \\
\text { Cap. }\end{array}$ & $\begin{array}{c}\text { No. of } \\
\text { Companies }\end{array}$ & Year & $\begin{array}{c}\text { Market } \\
\text { Cap. }\end{array}$ & $\begin{array}{c}\text { No. of } \\
\text { Companies }\end{array}$ \\
\hline 2000 & 130.1 & 225 & 2007 & 509.9 & 351 \\
\hline 2001 & 103.4 & 230 & 2008 & 267.4 & 374 \\
\hline 2002 & 110.6 & 216 & 2009 & 421.2 & 379 \\
\hline 2003 & 140.0 & 203 & 2010 & 542.6 & 400 \\
\hline 2004 & 214.3 & 230 & 2011 & 446.2 & 426 \\
\hline 2005 & 308.4 & 255 & 2012 & 523.4 & 438 \\
\hline 2006 & 437.7 & 284 & 2013 & 593.5 & 450 \\
\hline
\end{tabular}

Source: authors' own.

To allow for measurement consistency we remove banks and insurance companies from our sample because their performance indicators cannot be interpreted identically as those for the nonfinancial firms. For example, high leverage that constitutes a standard for financial firms is likely to signal distress for nonfinancial firms. We exclude firm-years with a negative book value of equity. Whenever possible we use yearly consolidated financial statements. We use individual financial statements when a company publishes only this type of financial statement. As an empirical matter, whenever individual data is missing, we code it as NA. To reduce the effect of possibly spurious outliers, we winsorize all the financial ratios as in Fama and French (1992), i.e. we set the top and bottom half percent values equal to the values corresponding to the $995^{\text {th }}$ and $5^{\text {th }}$ permille of each ratio's distribution. 
Our returns are reported in Polish zloty (PLN) and monthly excess returns are returns in excess of the one-year Polish Government bond rate. We consider Poland's one-year government bond rates as a good proxy for the risk-free rate for two reasons. We use the Bloomberg database to derive riskfree rates.

\section{FINDINGS}

\subsection{Risk factor premia}

The two asset pricing models that we use in our research consist of three different risk factors: MKT, SMB and HML. We analyze premia on particular risk factors together with the analysis of the risk-free rate and two potential candidates of proxy for market return. Table 4 summarizes the descriptive statistics of risk factor premia and component data in 2000-2013.

Table 4

Summary statistics for risk factor premia

We examine WSE risk premia throughout the period of January 2000-December 2013. We form the risk factors $(2 \times 3)$ by sorting stocks into portfolios at the end of June of each year. We construct the 6 value-weight portfolios formed on size and book-to-market. Stocks are divided into small and big category using median, whereas B/M breakpoints are the $30^{\text {th }}$ and $70^{\text {th }}$ percentiles. The size factor is constructed using the 6 value-weight portfolios formed on

$\mathrm{B} / \mathrm{M}$ and size. SMB returns are the equal-weight average of the returns on the three small stock portfolios for each market minus the average of the returns on the three big stock portfolios. HML returns are equal-weight averages of the returns on the two value stock portfolios for each market minus the average of the returns on the two growth stock portfolios. Returns are in PLN. MKT is the value-weight return on the market proxy (own market) minus the national risk-free rate (1Y Polish government bonds). Mean and Std dev are the mean and standard deviation of the return, and t-Mean is the ratio of mean to its standard error

\begin{tabular}{l|c|c|c|c|c|c}
\hline & Rf_1Y & WIG & own market & MKT & SMB & HML \\
\hline Mean & 0.35 & 0.84 & -0.26 & -0.62 & 1.39 & -0.66 \\
\hline Std dev & 0.28 & 6.62 & 7.59 & 7.62 & 6.50 & 8.96 \\
\hline t-Mean & 16.26 & 1.65 & -0.45 & -1.05 & 2.78 & -0.96 \\
\hline
\end{tabular}

Source: authors' own.

For the period of 2000-2013, the average monthly return on the risk-free asset in Poland equals $0.35 \%$ and is statistically significant $(t=16.26)$. The volatility of the return on $1 Y$ government bonds is rather low-the corresponding standard deviation is close to zero. Conversely, all other 
analyzed covariates and component data are highly volatile. Their standard deviations range between $6.50 \%$ and $8.96 \%$. This affects t-statistics, being below the conventional two-standard-errors bound. The only exception is the SMB premium, statistically significant $(t=2.78)$. This result is not that surprising because our time series is relatively short in comparison with asset pricing tests in advanced markets (e.g. in the USA, typical tests are based on over 300 monthly observations compared to our 168 months under research).

We shortlist two candidates to proxy market return on the WSE: own market, which is the value-weight return of all stocks from our sample as in Fama and French (1992), and WIG - the official index of the WSE that comprises all companies listed in the Main List that meet the base eligibility criteria. The historical WIG monthly average return is positive and equals $0.84 \%$. Own market return equals on average $-0.26 \%$. Both are accompanied by high volatilities. On the one hand, using own market proxy seems problematic as it yields a negative average monthly premium. ${ }^{2}$ However, this estimate lacks statistical significance, so we should not base our choice on its negative average value. On the other hand, the WIG return estimate is on average positive but still statistically insignificant $(\mathrm{t}=1.65)$. Using the WIG in our regressions might also distort models' performance and mislead with respect to the returns of big stocks, implying increased reliance on shorting in order to benefit from pricing anomalies. This is particularly true for size and value strategies. Therefore we advocate that own market proxy is more appropriate in asset pricing tests as it matches the true sample and is not artificially skewed towards big stocks. Ultimately, constructing a MKT factor with own market proxy results in the MKT premium being $-0.62 \%$ on average. $^{3}$

We report risk factor premia for the covariates used in the FF3F model. We observe an outstanding, statistically significant average monthly SMB premium of $1.39 \%$ (std dev of $6.50 \%$ ). This is particularly interesting because this monthly average is over five times higher than the value of this estimate originally reported by Fama and French (1993) for the U.S. stock

\footnotetext{
${ }^{2}$ We believe that the reason for the negative historical returns of this market return measure is that our own market does not include companies from the banking sector, which in the period of $2000-2013$ produced $+213 \%$ return, whereas WIG produced $+184 \%$ (i.e. the contribution of banks had a return-enhancing impact on the WIG index). In the same time, the banks' market capitalization amounted to almost $42 \%$ of the total WIG capitalization $(350,911$ million PLN vs. 840,780 million PLN) (WSE, 2014). As a result, own market proxy introduces a downward bias in the historical performance.

${ }^{3}$ For comparison, when we run our tests with the WIG market proxy, we arrive at the MKT monthly premium of $0.49 \%$.
} 
market in the initial 1963-1991 period: $0.27 \%{ }^{4}$ We argue that small stocks listed on the WSE tend to yield higher returns than their U.S. counterparts due to the majority of foreign institutional investors directing their capital solely at the WSE blue chip companies. Another salient feature is the negative sign of the value premium. Hereto we report a HML average monthly return of $-0.66 \%$ (std dev of $8.96 \%$ ). On the WSE, low B/M stocks outperform high $\mathrm{B} / \mathrm{M}$ stocks, which is a typical situation when the economy is expanding. It has the opposite sign of the HML premium reported by Fama and French (1993) for the U.S. stock market (0.40\%), which is an example of a mature, advanced market. Importantly, our estimate of the HML premium is not really reliable because it is below the traditional twostandard-error bound.

In Table 5 we show the correlation matrix for the set of factors used in both models.

\section{Table 5}

Pairwise correlations of the risk factor premia

Table 5 presents the Pearson's correlation coefficients of risk factors used in our models. MKT is the value-weight return on the market portfolio of the national market proxy index minus the national risk-free rate; SMB (small minus big) is the size factor; HML (high minus low $\mathrm{B} / \mathrm{M}$ ) is the value factor. The $2 \times 3$ factors are constructed using separate sorts of stocks into two size groups and three $\mathrm{B} / \mathrm{M}$ groups (HML). Table ***, **, and * indicate significance at the $1 \%, 5 \%$, and $10 \%$ levels, respectively

\begin{tabular}{c|c|c|c}
\hline & MKT & SMB & HML \\
\hline MKT & 1 & & \\
\hline SMB & -0.04 & 1 & \\
\hline HML & $-0.18^{* *}$ & $-0.30^{* * *}$ & 1 \\
\hline
\end{tabular}

Source: authors' own.

On the WSE there are two statistically significant pairwise correlations between the factors: HML with SMB and HML with MKT. In particular we report relatively the high and negative relationship of the value and market factor, significant at the $1 \%$ level. Interpretation thereof is a little problematic, as we do not know which effect outweighs: the negative correlation of companies with high book-to-market ratios (value stocks) with the market, or the positive correlation of companies with low book-to-market

\footnotetext{
${ }^{4}$ Here and in further analysis we discuss our results and provide analogous estimates from the pioneering research in this field by Fama and French (1993). We acknowledge the differences in market characteristics and periods under research, which is why we abstain from comparing the estimates, and rather, we use the U.S. study as a background illustration.
} 
ratios (growth stocks) and the market. In any case, the relationship is in line with the analogous study of Fama and French (1993) on the U.S. sample, who report a correlation coefficient of -0.38 . Similarly, we report the negative correlation of HML with SMB of -0.30 against -0.08 documented for the U.S. market, which is no surprise as small stocks tend to have similar returns as growth stocks, whereas big stocks follow similar path of returns as value stocks. Although we are inclined to think that MKT and SMB together seem to partially explain the variation in stock returns conventionally assigned to HML, this is not necessarily the case due to the specificity of asset pricing tests.

\subsection{Excess returns for the set of univariate LHS portfolios}

Table 6 presents summary statistics for ten univariate portfolios formed separately on size, B/M, momentum, profitability, and investment. We report the average portfolio's return, standard deviation, and t-statistic of its return, minimum and maximum count of stocks in each portfolio.

Table 6

Summary statistics for the LHS portfolio excess returns

In line with the conventional view, at the end of June of each year, we construct 10 univariate portfolios. We sort stocks on size (small and big market cap), B/M (high and low B/M), lagged momentum (winner and loser), profitability (robust and weak OP), and investment (conservative and aggressive investment). We use $30^{\text {th }}$ and $70^{\text {th }}$ percentiles to split stocks in each category. Mean and Std dev are the mean and standard deviation of the average monthly portfolio return, and t-Mean is the ratio of mean to its standard error. N_min and N_max are the minimum and maximum number of stocks included in a given portfolio

\begin{tabular}{|c|c|c|c|c|c|c|c|c|c|c|}
\hline & $\begin{array}{l}\overline{\overline{\widetilde{J}}} \\
\text { है }\end{array}$ & $\frac{.00}{m}$ & 趸 & 容 & 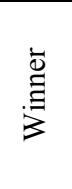 & 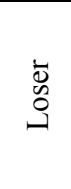 & 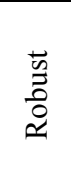 & $\begin{array}{l}\frac{y}{J} \\
3\end{array}$ & 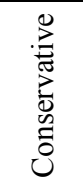 & 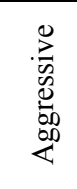 \\
\hline Mean & 0.20 & -0.65 & -0.60 & -1.49 & 1.41 & 0.91 & 0.53 & -1.65 & -1.18 & -0.83 \\
\hline Std dev & 9.45 & 7.68 & 8.32 & 10.19 & 8.27 & 8.63 & 6.81 & 11.79 & 10.13 & 10.33 \\
\hline$t$-Mean & 0.28 & -1.09 & -0.93 & -1.90 & 2.21 & 1.36 & 1.02 & -1.81 & -1.51 & -1.04 \\
\hline $\mathrm{N}$ max & 123 & 117 & 119 & 116 & 119 & 120 & 112 & 118 & 124 & 115 \\
\hline N_min & 28 & 24 & 28 & 22 & 21 & 22 & 18 & 24 & 27 & 21 \\
\hline
\end{tabular}

Source: authors' own.

Initially we were concerned with the number of stocks in the LHS portfolios, as the Polish stock market has a short history and is still at an early stage, low-scale enterprise in comparison to the U.S., the UK and 
German stock exchanges. However, it has been growing rapidly so more and more companies were being listed on the WSE. Ultimately, the population of stocks in our univariate portfolios ranges from 21 to 124 , which is already a good sample to run an asset pricing model.

An inspection of Table 6 provides some interesting conclusions. First, LHS portfolios produce a wide range of average monthly excess returns, from $-1.65 \%$ per month for Weak profitability firms up to $1.41 \%$ per month for Winner stocks. All LHS portfolio returns are accompanied by notably high variation in their values (average std dev on all ten univariate portfolios of 9.16\%). Our study provides another proof of De Santis' (1997) observation that emerging stock markets are characterized by persistently higher volatility than advanced markets. Second, in each sort the LHS portfolios have returns that work in line with the pre-assumed anomaly, i.e. Small stocks outperform Big stocks, High B/M stocks outperform Low B/M stocks, etc. The only exception are portfolios in the investment sort - they perform counterintuitively since in our sample Aggressive-investment firms outperform Conservative-investment ones. This is against the conventional view on investment anomaly according to which firms characterized by conservative investment (usually associated with value stocks) outperform firms aggressively investing (usually associated with growth stocks).

Due to short sample and high standard deviations, our excess returns are below two standard errors from zero for most of the LHS portfolios. Thus, the related estimates lack statistical significance, and therefore we do not base our practical implications on the averages for the period of 2000-2013. Instead we provide historical information on generic trading strategies on the WSE, and we present the results in Figure 1.

Panel B confirms the superior performance of small equities - Smallstock portfolio outperforms the corresponding Big-stock portfolio, particularly in the period preceding the global financial crisis. In terms of performance, the former produces on average a $0.20 \%$ monthly return, whereas the latter delivers an average of $0.65 \%$. Furthermore, it is interesting to see that the large equities fail to surpass smaller stocks even during times of economic downturn. The relative performance of value $v s$. growth stocks (Panel C) resembles the former results concerning small and big stocks in the way that the related anomaly (value effect) is evidently stronger in the period before the 2007-2008 crisis. On average, High-book-to-market stocks deliver higher returns than Low-book-to-market-stocks, but both portfolios have a negative monthly mean excess return of $-0.60 \%$ and $-1.49 \%$ respectively. Most recently (since 2010), both strategies keep yielding negative returns. The two momentum-oriented strategies closely resemble 

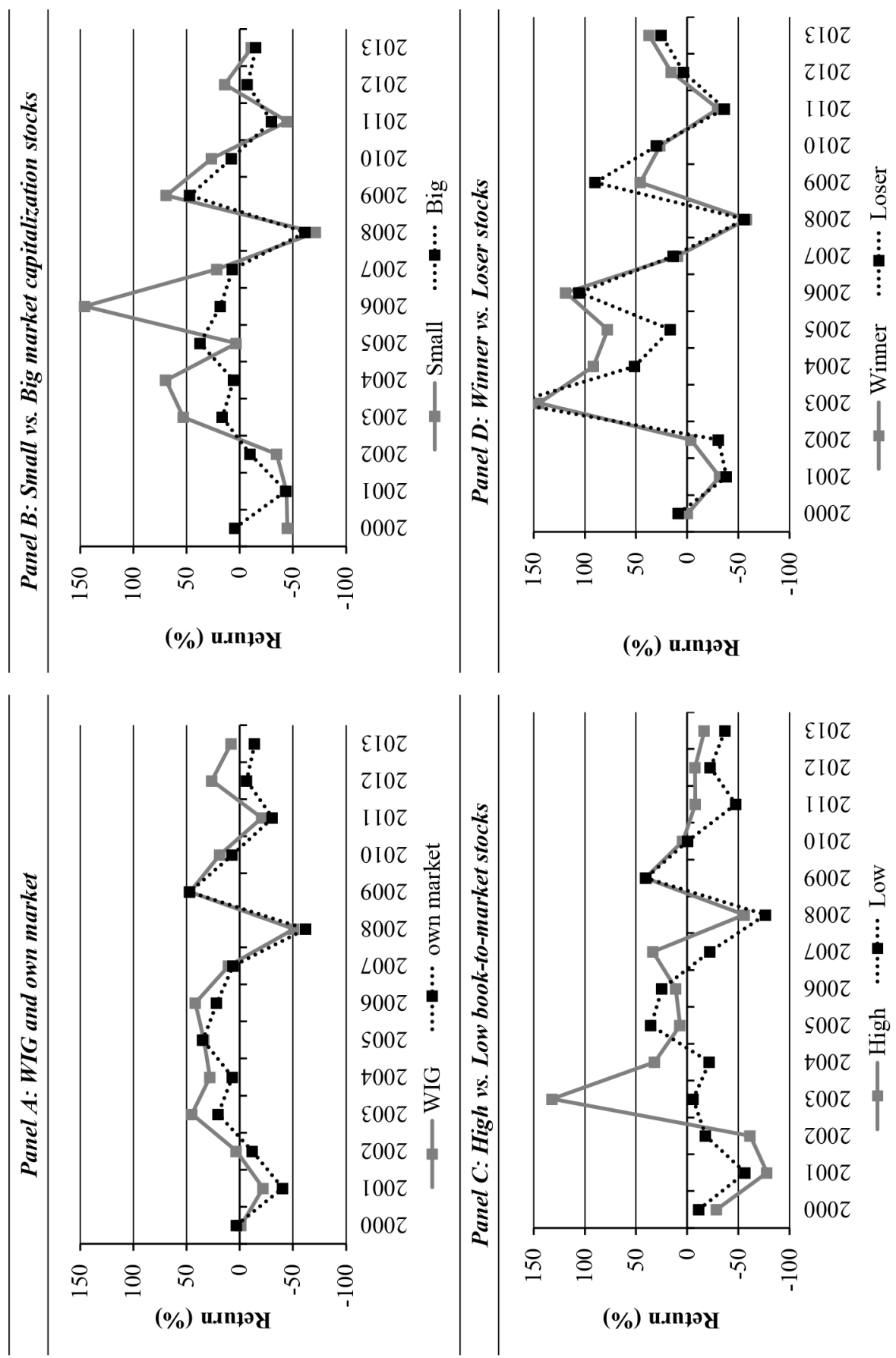


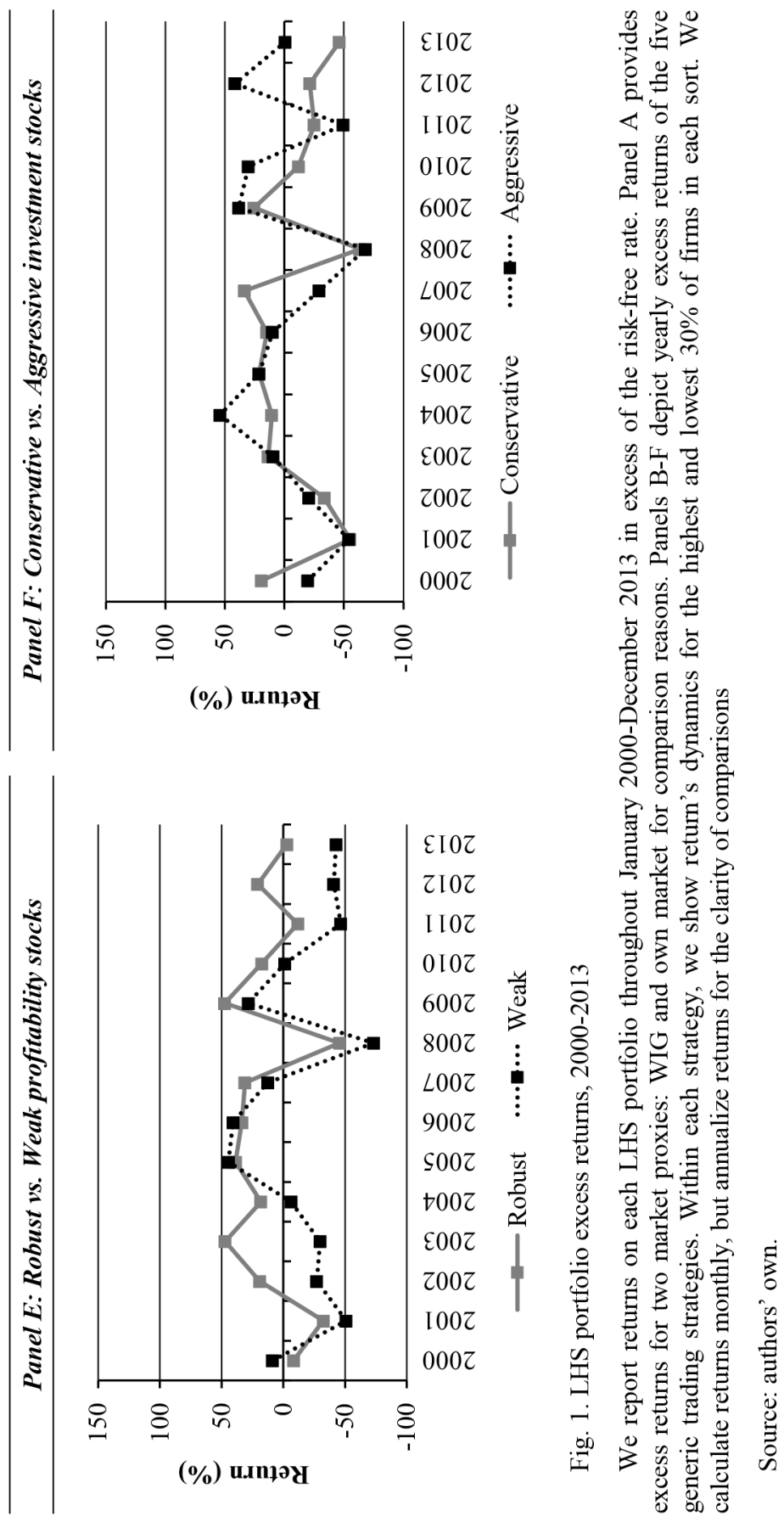


each other, as illustrated in Panel D, however the difference in mean returns is considerable: Winner-stock portfolio delivers $1.41 \%$ monthly excess return, while Loser-stock portfolio brings $0.91 \%$. Panel E highlights the superiority of the Robust-stock portfolio over the corresponding Weak-stock portfolio. Robust-profitability stocks yield a positive $0.53 \%$ return. This is not the top performing portfolio in the sample, but the return is still materially bigger than the return of Weak-profitability stocks which on average yield a negative $-1.65 \%$ excess return. The difference in results is high in the beginning of our sample period, but it has risen more recently (starting from 2009) too. Furthermore, the return of the more profitable stocks is also significantly less volatile (std dev of 6.81 vs. 11.79) which is evident from the visual inspection of the plot. Finally, both the Conservativestock portfolio and the Aggressive-stock portfolio yield negative returns, at $1.18 \%$ and $-0.83 \%$ respectively. The relative performance of the two investment-oriented strategies is unreliable - the differences are generally short-lasting and frequently change sign (Panel F).

\subsection{Abnormal returns on the WSE}

The time-series regressions with two sets of risk factors on ten LHS portfolios deliver a multitude of insights about stock performance and anomaly persistence in the Polish stock market. We discuss them together with the general APM's performance.

Table 7

Intercept estimates for CAPM and FF3F regressions on 10 LHS portfolios individually, 2000-2013

We test APMs' performance on an individual LHS portfolio level for the period of January

2000-December 2013. We use CAPM and FF3F to explain returns on 10 univariate LHS portfolios. For each regression, the table shows $\alpha$ - the intercept (in percent, monthly) and $t(\alpha)$ - the ratio of the intercept to its standard error

\begin{tabular}{|c|c|c|c|c|c|c|c|c|c|c|}
\hline & $\underset{\bar{\Xi}}{\bar{\Xi}}$ & 些 & 馬 & 光 & $\underset{\Xi}{\grave{\Xi}}$ & 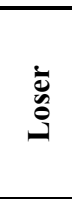 & $\begin{array}{l}\overrightarrow{0} \\
\overline{0} \\
\ddot{\theta} \\
\simeq\end{array}$ & 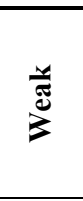 & 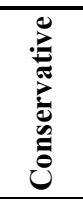 & 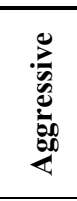 \\
\hline$\alpha_{\mathrm{CAPM}}$ & 0.72 & -0.03 & -0.20 & -0.73 & 1.88 & 1.46 & 0.98 & -0.82 & -0.51 & -0.17 \\
\hline$t\left(\alpha_{C A P M}\right)$ & 1.34 & -0.48 & -0.38 & -2.46 & 4.16 & 3.62 & 3.08 & -1.78 & -1.13 & -0.34 \\
\hline$\alpha_{\mathrm{FF} 3 \mathrm{~F}}$ & 0.01 & 0.05 & -0.06 & -0.85 & 1.26 & 0.98 & 1.12 & -1.05 & -0.47 & -0.42 \\
\hline$t\left(\alpha_{F F 3 F}\right)$ & 0.02 & 1.12 & -0.16 & -3.46 & 3.20 & 2.84 & 3.61 & -2.28 & -1.02 & -0.84 \\
\hline
\end{tabular}

Source: authors' own. 
The performance of size anomaly disappoints. Although Small-stock portfolio clearly delivers higher alpha than the corresponding Big-stock portfolio $(0.72 \%$ vs. $-0.03 \%)$ in terms of CAPM, the results are not statistically significant as evidenced by small t-stats (1.34 and -0.48). FF3F validates these conclusions. Controlling for size effect on the right hand side of the regression makes almost any indication of size anomaly disappear. The intercept estimates are equal to only $0.01 \%$ and $0.05 \%$, and the corresponding t-stats are negligible (0.02 and 1.12). Regarding value anomaly, there is some evidence for risk-adjusted abnormal performance, however restricted to growth stocks and negative in sign. Low-stock portfolio yields a CAPM alpha of $-0.73 \%$, and a FF3F alpha of $-0.85 \%$. Both estimates are statistically significant ( $t$-stats of -2.46 and -3.46 respectively). Our results imply an increased reliance on shorting in any attempt to capture superior profits. Interestingly, both momentum-portfolios deliver strong, positive risk-adjusted returns. In accordance with CAPM, the Winnerportfolio yields an alpha of $1.88 \%$, whereas the Loser-portfolio produces an alpha of $1.46 \%$. Both estimates are statistically significant as confirmed by tstats of 4.16 and 3.62, respectively. Note that the winners offer the highest alpha across all portfolios. The FF3F model further validates the anomalous performance of both portfolios. The corresponding FF3F's alphas are 1.26\% for Winners and $0.98 \%$ for Losers. Again, both estimates are statistically significant (t-stats of 3.20 and 2.84). Although each of the two momentumrelated portfolios yield significant alphas regardless of the pricing model used, the inference and implications are to some extent ambiguous because both portfolios share the same sign. Clearly, only an evident difference in the performance of the two portfolios can shift investor's preference from one of the contrasting sorts to the opposite. The profitability anomaly is by far more pronounced. The Robust-stock portfolio delivers $0.98 \%$ CAPM alpha $(\mathrm{t}=3.08)$, while the Weak-stock portfolio yields negative $-0.82(\mathrm{t}=-1.78)$. The FF3F estimates support these results. The Robust-profitability equities produce an alpha of $1.12 \%(\mathrm{t}=3.61)$, which is again remarkably higher than the Weak-profitability stocks' alpha of $-1.05 \%(\mathrm{t}=-2.28)$. As it transpires, both models provide empirical evidence of the profitability anomaly. With respect to the investment sorts, the results are weak in terms of statistical significance. CAPM alphas are at $-0.51 \%(\mathrm{t}=-1.13)$ and $-0.17 \%(\mathrm{t}=-0.34)$ for Conservative-investment and Aggressive-investment stocks respectively. The corresponding FF3F alphas equal to $-0.47 \%$ and $-0.42 \%$, and both are statistically insignificant (t-stats of -1.02 and -0.84 ). 
Table 8

Summary statistics for CAPM and FF3F regressions on 10 LHS portfolios at an aggregated level, 2000-2013

We test APMs' performance at an aggregated level for the period of January 2000-December 2013. We use CAPM and FF3F to explain returns on 10 univariate LHS portfolios. For each set of regressions, the table shows the GRS statistic (with corresponding $p$-values) testing whether the expected values of all intercepts in a set of 10 univariate LHS portfolio regressions are zero. $A|\alpha|$ is the average absolute intercept (in percent); $A \mathrm{~s}(\alpha)$ is the average standard error of the intercept; $\mathrm{SR}(\alpha)$ is the Sharpe Ratio for the 16 intercepts; $A\left(\mathrm{R}^{2}\right)$ is the average $\mathrm{R}^{2}$ of the regressions; and $A\left(\operatorname{adj} . \mathrm{R}^{2}\right)$ is the average $\mathrm{R}^{2}$ adjusted for the number of explanatory variables in an APM

\begin{tabular}{c|c|c|c|c|c|c|c}
\hline $\boldsymbol{A P M}$ & $\boldsymbol{G R S}$ & $\boldsymbol{G R S}(\boldsymbol{p}$-val) & $\boldsymbol{A}|\boldsymbol{\alpha}|$ & $\boldsymbol{A} \boldsymbol{s}(\boldsymbol{\alpha})$ & $\boldsymbol{S R}(\boldsymbol{\alpha})$ & $\boldsymbol{A}\left(\boldsymbol{R}^{2}\right)$ & $\boldsymbol{A}\left(\boldsymbol{a d j} . \boldsymbol{R}^{\mathbf{2}}\right)$ \\
\hline CAPM & 5.96 & 0.000 & 0.750 & 0.399 & 0.61 & 0.65 & 0.65 \\
\hline FF3F & 5.14 & 0.000 & 0.626 & 0.358 & 0.58 & 0.74 & 0.73 \\
\hline
\end{tabular}

Source: authors' own.

According to the major tests for the robustness of an asset pricing model, on a sample of the WSE stocks the FF3F model performs slightly better than CAPM. The GRS statistic equals 5.14 for the three-factor model and to 5.96 for the one-factor model. Conditional on the distribution on returns and residuals, the GRS test rejects both models at any level of significance. Average absolute alpha is higher for CAPM $(0.750 \%)$ than for FF3F $(0.626 \%)$. Our results confirm a stylized fact that in general a one-factor model produces larger anomalous returns. The estimates are also more volatile - the average standard error of alpha is higher for CAPM (0.399 vs. 0.358). The difference in Sharpe ratios (0.61 for CAPM and 0.58 for FF3F) resembles the difference in average absolute alphas. Both $\mathrm{R}^{2}$ statistics are relatively higher for the three-factor model (average $\mathrm{R}^{2}$ of $74 \%$ and average adjusted $\mathrm{R}^{2}$ of $65 \%$ for $\mathrm{FF} 3 \mathrm{~F} v$ s. $65 \%$ and $65 \%$ for CAPM), as reasonably expected given its most complex formulation. Therefore, we argue that despite being less popular in the investment practice in the CEE region (Zaremba and Konieczka, 2015), FF3F better explains the common variation in stock returns on the WSE, thus its intercept is a more reliable measure of the local investment opportunities.

\subsection{Abnormal returns in bull and bear market}

Last but not least, we verify how abnormal returns change once we account for the different macroeconomic conditions and investment climate. Therefore, we divide our sample into two sub-periods that reflect the bull 
(Table 9, Panel A) and the bear market (Table 9, Panel B). In doing so, we also show how abnormal investment opportunities evolved in times of rapid growth and development of the WSE.

\section{Table 9}

Summary statistics for CAPM and FF3F regressions to explain monthly excess returns on the LHS portfolios for WSE, separately for 2000-2006 and 2007-2013

We test APMs' performance at an aggregated level, separately for the period of January 2000-

December 2006 and January 2007-December 2013. We use CAPM and FF3F to explain returns on 10 univariate LHS portfolios. For each set of regressions, the table shows the GRS statistic (with corresponding $p$-values) testing whether the expected values of all intercepts in a set of 10 univariate LHS portfolio regressions are zero. $A|\alpha|$ is the average absolute intercept (in percent); $A \mathrm{~s}(\alpha)$ is the average standard error of the intercept; $\mathrm{SR}(\alpha)$ is the Sharp Ratio for the 16 intercepts; $A\left(\mathrm{R}^{2}\right)$ is the average $\mathrm{R}^{2}$ of the regressions; and $A\left(\operatorname{adj} . \mathrm{R}^{2}\right)$ is the average $\mathrm{R}^{2}$ adjusted for the number of explanatory variables in an APM

\begin{tabular}{l|c|c|c|c|c|c|c}
\hline \multicolumn{1}{c|}{$\boldsymbol{A P M}$} & $\boldsymbol{G R S}$ & $\boldsymbol{G R S}(\boldsymbol{p}$-val $)$ & $\boldsymbol{A}|\boldsymbol{\alpha}|$ & $\boldsymbol{A} \boldsymbol{s}(\boldsymbol{\alpha})$ & $\boldsymbol{S R}(\boldsymbol{\alpha})$ & $\boldsymbol{A}\left(\boldsymbol{R}^{2}\right)$ & $\boldsymbol{A}\left(\boldsymbol{a d j} \mathbf{.} \boldsymbol{R}^{2}\right)$ \\
\hline \multicolumn{2}{l|}{ Panel A: $2000-2006$} & & & & & & \\
\hline CAPM & 4.86 & 0.00 & 0.94 & 0.01 & 0.81 & 0.58 & 0.57 \\
\hline FF3F & 3.56 & 0.00 & 0.76 & 0.01 & 0.73 & 0.71 & 0.70 \\
\hline \multicolumn{2}{l|}{ Panel B: $2007-2013$} & & & & & & \\
\hline CAPM & 2.38 & 0.02 & 0.65 & 0.00 & 0.57 & 0.74 & 0.73 \\
\hline FF3F & 2.52 & 0.01 & 0.57 & 0.00 & 0.59 & 0.81 & 0.80 \\
\hline
\end{tabular}

Source: authors' own.

The evidence in Table 9 implies that the estimates of abnormal returns are materially different between the two subsamples. The earlier sub-period is to be associated with stable macro-conditions, a growing economy, and no turbulence on the WSE. Based on current academic narratives, we expected to document lower abnormal returns for the period of 2000-2006 in comparison to 20072013, when Polish capital market, along with the global financial markets, was subject to crisis, uncertainty, and the consequent low appetite for risk connected to equity investments. We also expected that due to the gradually growing influence of foreign investors on the trade on the WSE (Table 10), who tend to withdraw capital from emerging stock markets in the crisis aftermath, there would be a strong detachment of prices from fundamentals in the second subperiod, as observed by the estimate of the intercept in the asset pricing models. Counterintuitively, we report higher abnormal profits for the bull than for the bear period. Average absolute alphas for the 2000-2006 sample are $0.94 \%$ and $0.76 \%$ for CAPM and FF3F respectively; they decrease to $0.65 \%$ and $0.57 \%$ in the 2007-2013 sample. Under our assumptions, the GRS test statistically supports these estimates. In particular, CAPM, with a F-GRS statistic of 2.38 is 
no longer rejected at the $1 \%$ significance level. We attribute this effect mainly to the profitability anomaly - we report higher alphas with respect to the related sorts for the FF3F model. Mirroring the decline in average absolute alphas, the Sharpe ratios decrease accordingly, from 0.81 and 0.73 to 0.57 and 0.59 for the CAPM and FF3F models respectively. Since the Sharpe ratio is itself a primary component of the GRS test, it is bound to be higher for the FF3F model. The goodness-of-fit, as measured by the average $\mathrm{R}^{2}$ and average adjusted $\mathrm{R}^{2}$, is noticeably higher for the later period. Each metric increases by at least 10 percentage points, regardless of the model. Although baseline estimates are biased upward under normality assumptions, in accordance with Zhou (1993), we expect relative inference to remain valid under alternative distributions.

Table 10

Investors' composition on the WSE, 2002-2013

Turnover volume on the WSE created by particular types of investors throughout 2002-2013. Data derived from www.gpw.pl

\begin{tabular}{l|l|l|l|l|l|l|l|l|l|l|l|l}
\hline & $\mathbf{2 0 0 2}$ & $\mathbf{2 0 0 3}$ & $\mathbf{2 0 0 4}$ & $\mathbf{2 0 0 5}$ & $\mathbf{2 0 0 6}$ & $\mathbf{2 0 0 7}$ & $\mathbf{2 0 0 8}$ & $\mathbf{2 0 0 9}$ & $\mathbf{2 0 1 0}$ & $\mathbf{2 0 1 1}$ & $\mathbf{2 0 1 2}$ & $\mathbf{2 0 1 3}$ \\
\hline Foreign (institutional) & $35 \%$ & $32 \%$ & $33 \%$ & $41 \%$ & $31 \%$ & $33 \%$ & $43 \%$ & $36 \%$ & $47 \%$ & $47 \%$ & $48 \%$ & $47 \%$ \\
\hline Retail (individual) & $29 \%$ & $29 \%$ & $35 \%$ & $26 \%$ & $35 \%$ & $30 \%$ & $18 \%$ & $27 \%$ & $19 \%$ & $18 \%$ & $18 \%$ & $15 \%$ \\
\hline Institutional (domestic) & $36 \%$ & $39 \%$ & $32 \%$ & $33 \%$ & $34 \%$ & $37 \%$ & $39 \%$ & $37 \%$ & $34 \%$ & $35 \%$ & $34 \%$ & $38 \%$ \\
\hline
\end{tabular}

Source: authors' own.

To recap, the findings indicate there were relatively more investment opportunities (as measured by the average absolute alpha) on the WSE before the global crisis of 2007-2008 than during and after it. We see two possible explanations. First, the asset pricing skills on the WSE improved due to the growing influence of foreign institutional investors, and simultaneously due to the weakening influence of generally unskilled retail investors on trade and pricing (Table 10 presents how much turnover volume has been created by particular investor groups on the WSE during our sample). The second explanation is that the effect of international portfolio rebalancing, which in times of crisis usually means capital outflows for emerging stock markets, was immaterial for the pricing of stocks on the WSE. This suggests that international investors did not perceive Polish equity like other emerging equities, most likely due to the outstanding performance of the Polish economy. ${ }^{5}$

\footnotetext{
${ }^{5}$ During the post-crisis years of 2008-2011, Poland experienced 4.8, 1.7, 3.8, and 4.4 percent growth while the whole European Union grew by $0.8,-4.0,1.8$, and 1.6 percent respectively (CIA World Factbook, 2015).
} 


\section{CONCLUSIONS}

Joining the academic discussion on investment opportunities provided by emerging markets, we analyze the abnormal returns in the Polish stock market using asset pricing models. We follow the conventional view that anomalies emerge in various circumstances because particular patterns in average stock returns are left unexplained by an asset pricing model, thus abnormal investment opportunities occur. Our implementation strategy slightly differs from the classic procedures. We diverge whenever it is necessary to account for the limitations of the Polish sample, above all its size.

By investigating particular trading strategies in a time-varying investment environment, we deliver sound empirical conclusions concerning two important aspects of asset pricing on the WSE. First, we examine returns' plots and abnormal returns of the five generic trading strategies and infer on potential trading opportunities. Once stock market practitioners exploit them, it is likely to contribute to the greater informational efficiency of the Polish stock market. To this point, we report that size anomaly is not statistically supported both under the CAPM and FF3F model. Once the SMB factor is included in the model's specification, abnormal returns decline to virtually $0 \%$. We document negative risk-adjusted performance of growth (Low bookto-market) stocks, however trading strategy based on value effect relies foremost on shorting. Momentum anomaly is ambiguous as both extreme strategies yield positive, statistically significant returns and, once employed in each asset pricing models, they produce positive and statistically significant alphas. Profitability-based portfolios are not the top-performers, but the anomaly itself is the most evident and statistically supported with respect to estimation results and visual investigation of the yearly return plot. Finally, investment-related abnormal returns are not significant.

Second, we scrutinize the development of the stock market over time (measured by pricing accuracy), at the same time accounting for the potential impact of global and local events on pricing on the WSE at an aggregate level. We document that CAPM performs well in the emerging stock market of Poland. As expected, FF3F's performance is more robust in relative terms, but the improvement over CAPM in the full sample is only marginal. The model correctly adjusts for size and value effects. Once separately employed on the two sub-periods, the FF3F model performs relatively better only in the bull market sample. In the bear market sample it has a slightly weaker performance than CAPM. The latter, in the 2007-2013 sub-period, is not rejected even at the $1 \%$ significance level by the standard GRS test. 
Importantly, our research design allows us to deliver novel insights into the investment opportunities with respect to the WSE as a whole: our findings suggest that in the period 2000-2013, stock market practitioners were able to achieve abnormal returns on the WSE estimated at $0.75 \%$ monthly by CAPM or $0.63 \%$ monthly by the FF3F model.

Furthermore, we put a particular emphasis on foreign investors' activity and their contribution to the overall pool of asset-pricing skill. By doing so, we expand the traditional inference beyond the pure model/anomaly verification. Our findings clearly indicate a stark decline in abnormal investment opportunities between the two sub-periods, the bull and bear market. The results are counterintuitive in that they are in contrast to the original expectations. We are inclined to believe that the lower abnormal returns in recent years are likely to be explained by the changing composition of the investor mix on the WSE - the increasing share of foreign institutional investors and the decreasing share of retail investors in turnover volume contributed to higher asset pricing skill and the lower level of mispricing. The growing market size is probably another factor that further contributes to the diminishing abnormal returns of the strategies under consideration. A potentially interesting area for future research would be to explore if, given the specific characteristics of post-transition economies and their financial markets, the results obtained for the WSE are representative for other emerging markets in Central and Eastern Europe.

\section{REFERENCES}

Asness, C., Frazzini, A., The devil in HML's details, "Journal of Portfolio Management", 39(4), pp. 49-68, 2013.

Baker, M., Wurgler, J., Investor sentiment and the cross-section of stock returns, "The Journal of Finance", 61(4), pp. 1645-1680, 2006.

Banz, R. W., The relationship between return and market value of common stocks, "Journal of Financial Economics", 9(1), pp. 3-18, 1981.

Barberis, N., Thaler, R., A survey of behavioral finance [in:] Constantinides, G., Harris, M., Shultz, R. (eds.), Handbook of the Economics of Finance, pp. 1053-1128. North-Holland, 2003.

Bialkowski, J., Otten, R., Emerging market mutual fund performance: evidence for Poland, "The North American Journal of Economics and Finance", 22(2), pp. 118-130, 2011.

Black, F., Capital market equilibrium with restricted borrowing, "The Journal of Business", 45(3), pp. 444-455, 1972.

Campbell, J. Y., Hilscher, J., Szilagyi, J., In search of distress risk, “The Journal of Finance”, 63(6), pp. 2899-2939, 2008.

Carhart, Mark M., On Persistence in Mutual Fund Performance, "The Journal of Finance", 52(1), pp. 57-82, 1997. 
Chan, L. K., Jegadeesh, N., Lakonishok, J., Momentum Strategies, “The Journal of Finance”, 51(5), pp. 1681-1713, 1996.

Chou, P. H., Ho, P. H., Ko, K. C., Do industries matter in explaining stock returns and assetpricing anomalies?, "Journal of Banking \& Finance", 36(2), pp. 355-370, 2012.

Chuhan, P., Are institutional investors an important source of portfolio investment in emerging markets? (vol. 1243), World Bank Publications, 1994.

Cohen, R. B., Gompers, P. A., Vuolteenaho, T., Who underreacts to cash-flow news? Evidence from trading between individuals and institutions, "Journal of financial Economics", 66(2), pp. 409-462, 2002.

Constantinides, G. M., Intertemporal asset pricing with heterogeneous consumers and without demand aggregation, "Journal of Business", pp. 253-267, 1982.

Cooper, M. J., Gulen, H., Schill, M. J., Asset growth and the cross-section of stock returns, "The Journal of Finance", 63(4), pp. 1609-1651, 2008.

Coval, J., Stafford, E., Asset Fire Sales (and Purchases) in Equity Markets, "Journal of Financial Economics", 86(2), pp. 479-512, 2007.

De Santis, G., Stock returns and volatility in emerging financial markets, "Journal of International Money and Finance", 16(4), pp. 561-579, 1997.

Daniel, K., Titman, S., Market reactions to tangible and intangible information, "The Journal of Finance", 61(4), pp. 1605-1643, 2006.

Dasgupta, A., Prat, A., Verardo, M., Institutional Trade Persistence and Long-Term Equity Returns, "The Journal of Finance", 66(2), pp. 635-653, 2011.

Edelen, R. M., Ince, O. S., Kadlec, G. B., Institutional Investors and Stock Return Anomalies, "Journal of Financial Economics", 119(3), pp. 472-488, 2016.

Fama, E. F., Efficient Capital Markets: A Review of Theory and Empirical Work, "The Journal of Finance", 25(2), pp. 383-417, 1970.

Fama, E. F., Efficient capital markets: II, “The Journal of Finance”, 46(5), pp. 1575-1617, 1991.

Fama, E. F., French, K. R., The cross-section of expected stock returns, "The Journal of Finance", 47(2), pp. 427-465, 1992.

Fama, E. F., French, K. R., Common risk factors in the returns on stocks and bonds, "Journal of Financial Economics", 33(1), pp. 3-56, 1993.

Fama, E. F., French, K. R., Profitability, investment and average returns, "Journal of Financial Economics", 82(3), pp. 491-518, 2006.

Fama, E. F., French, K. R., Dissecting anomalies, “The Journal of Finance”, 63(4), pp. 1653-1678, 2008.

Fama, E. F., French, K. R., A five-factor asset pricing model, "Journal of Financial Economics", 116(1), pp. 1-22, 2015.

Fama, E. F., MacBeth, J. D., Risk, return, and equilibrium: empirical tests, "The Journal of Political Economy", pp. 607-636, 1973.

Foster, G., Olsen, C., Shevlin, T., Earnings releases, anomalies, and the behavior of security returns, "Accounting Review", pp. 574-603, 1984.

Friend, I., Blume, M., Measurement of portfolio performance under uncertainty, "The American Economic Review", 60(4), pp. 561-575, 1970. 
Gibbons, M. R., Ross, S. A., Shanken, J., A test of the efficiency of a given portfolio, "Econometrica: Journal of the Econometric Society", pp. 1121-1152, 1989.

GPW, New rules of short selling on GPW in light of the European Union regulations, 2016. Available at: https://www.gpw.pl/krotka_sprzedaz_i_pozyczki_papierow_en

Grossman, S. J., Dynamic asset allocation and the informational efficiency of markets, "The Journal of Finance", 50(3), pp. 773-787, 1995.

Grossman, S. J., Stiglitz, J. E., On the impossibility of informationally efficient markets, "The American Economic Review”, 70(3), pp. 393-408, 1980.

Haugen, R. A., Baker, N. L., Commonality in the determinants of expected stock returns, "Journal of Financial Economics", 41(3), pp. 401-439, 1996.

Jegadeesh, N., Titman, S., Returns to buying winners and selling losers: implications for stock market efficiency, "The Journal of Finance", 48(1), pp. 65-91, 1993.

Jensen, M. C., Black, F., Scholes, M. S., The capital asset pricing model: some empirical tests, 1972.

King, M. A., Wadhwani, S., Transmission of volatility between stock markets, "Review of Financial Studies", 3(1), pp. 5-33, 1990.

Kogan, L., Papanikolaou, D., Investment shocks, firm characteristics and the cross-section of expected returns, Working paper, 2011.

Kuhn, T., The Structure of Scientific Revolutions. University of Chicago Press, Chicago 1970.

Lewellen, J., Nagel, S., Shanken, J., A skeptical appraisal of asset pricing tests, "Journal of Financial Economics", 96(2), pp. 175-194, 2010.

Lintner, J., The valuation of risk assets and the selection of risky investments in stock portfolios and capital budgets, "The Review of Economics and Statistics", pp. 13-37, 1965.

Longstaff, F. A., The subprime credit crisis and contagion in financial markets, "Journal of Financial Economics", 97(3), pp. 436-450, 2010.

Malkiel, B. G., The efficient market hypothesis and its critics, "The Journal of Economic Perspectives", 17(1), pp. 59-82, 2003.

McLean, R. D., Pontiff, J., Does academic research destroy stock return predictability?, "The Journal of Finance", 71(1), pp. 5-32, 2016.

Ohlson, J. A., Financial ratios and the probabilistic prediction of bankruptcy, "Journal of Accounting Research", pp. 109-131, 1980.

Pástor, L., Stambaugh, R. F., Liquidity Risk and Expected Stock Returns, "Journal of Political Economy" 111(3), pp. 642-685, 2003.

Pontiff, J., Woodgate, A., Share Issuance and Cross-Sectional Returns, "The Journal of Finance", 63(2), pp. 921-945, 2008.

Prorokowski, L., Roszkowska P., Comparison of practitioners' views on managing equity investments: evidence from Poland, "Baltic Journal of Management" 9(2), pp. 153-167, 2014.

PwC, IPO Watch Europe 2013. PwC, 2014. Retrieved from https://www.pwc.co.uk/assets/ pdf/ipo-watch-europe-2013.pdf

Schotman, P.C., Zalewska, A., Non-Synchronous Trading and Testing for Market Integration in Central European Emerging Markets, "Journal of Empirical Finance”, 13, pp. 462-494, 2006. 
Sharpe, W. F., Capital asset prices: a theory of market equilibrium under conditions of risk, "The Journal of Finance", 19(3), pp. 425-442, 1964.

Shiller, R. J., From efficient markets theory to behavioral finance, "The Journal of Economic Perspectives", 17(1), pp. 83-104, 2003.

Sloan, R., Do stock prices fully reflect information in accruals and cash flows about future earnings? Accounting Review, 71(3), pp. 289-315, 1996.

Stambaugh, R. F., On the exclusion of assets from tests of the two-parameter model: a sensitivity analysis, "Journal of Financial Economics", 10(3), pp. 237-268, 1982.

Waszczuk, A., A risk-based explanation of return patterns - evidence from the Polish stock market, "Emerging Markets Review", 15, pp. 186-210, 2013a.

Waszczuk, A., Do local or global risk factors explain the size, value and momentum trading payoffs on the Warsaw Stock Exchange?, "Applied Financial Economics", 23(19), pp. 1497$-1508,2013 b$.

WSE, WSE Fact book 2014. 2013 Data. Warsaw Stock Exchange, Warsaw 2014. Retrieved from https://www.gpw.pl/Fact_book_2014.

Zaremba, A., Konieczka, P., Are Value, Size and Momentum Premiums in CEE Emerging Markets only Illusionary?, "Czech Journal of Economics and Finance" (Finance a uver), 65(1), pp. 84-104, 2015.

Zhou, G., Asset-pricing Tests under Alternative Distributions, "The Journal of Finance", 48(5), pp. 1927-1942, 1993.

Received: October 2016, revised: November 2017

Acknowledgement: We gratefully acknowledge the guidance and many helpful comments from William Fuchs, Nicolae Garlenau, Emir Hrnjić, Robert Jalali, Dmitry Livdan, Terrance Odean, Marcin Owczarczuk, Panos Patatoukas, David Sraer, visiting scholar seminar participants at the Haas School of Business, UC Berkeley, and seminar participants at the Craig School of Business, CS Fresno. Last but not least, we give special thanks to the Editor and the two anonymous reviewers. 